\title{
O TRABALHO DOCENTE NA EDUCAÇÃo SUPERIOR BRASILEIRA: PERPETUAÇÕES DE CONTRARREFORMA
}

\section{EM UM CONTEXTO DE CRISE}

\author{
The teaching work in the brazilian higher education: \\ performances of counterreformation in a context of crisis \\ El trabajo docente en la educación superior brasileña: \\ perpetuaciones de contrarreforma en un contexto de crisis
}

RESUMO O presente artigo trata do trabalho docente no contexto de contrarreforma do Estado brasileiro, a partir das interpretações de vários autores sobre a perspectiva dos organismos internacionais, como Banco Mundial e Fundo Monetário Internacional, no âmbito das políticas de educação superior no Brasil, situando-as no contexto neoliberal. A questão problema que norteou a investigação foi: quais os impactos da contrarreforma do Estado para o trabalho docente na educação superior brasileira? O método de investigação foi o materialismo histórico dialético, que possibilitou a aproximação da totalidade e das contradições do fenômeno analisado. Os procedimentos metodológicos utilizados foram: levantamento e estudo teórico-bibliográfico a respeito da temática, resultando em uma abordagem qualitativa. Os resultados indicaram que a contrarreforma do Estado brasileiro, impulsionada pela reestruturação produtiva e sob a égide dos organismos internacionais, tem impactado no trabalho docente na educação superior, tornando-o intensificado, flexibilizado e precarizado.

Palavras-chave: Trabalho Docente. Educação Superior. CONTRARREFORMA. CRISE.

ABSTRACT This article deals with teaching work in the context of counterreformation of the Brazilian State, based on the interpretations of various authors on the perspective of international organizations, such as the World Bank and the International Monetary Fund, within the framework of higher education policies in Brazil, in the neoliberal context. The problem issue that guided the research was: what are the impacts of the State's counter-reform on teaching work in Brazilian higher education? The method of investigation was dialectical historical materialism, which made possible the approximation of the totality and contradictions of the phenomenon analyzed. The methodological procedures used were: survey and theoretical-bibliographic study on the subject, resulting in a qualitative approach. The results indicated that the counterreformation of the Brazilian State, driven by productive restructuring and under the aegis of international organizations,
Rodrigo Barbosa Bastos

Universidade Federal do Amapá - UNIFAP

Ilma de Andrade Barleta Universidade Federal do Amapá - UNIFAP

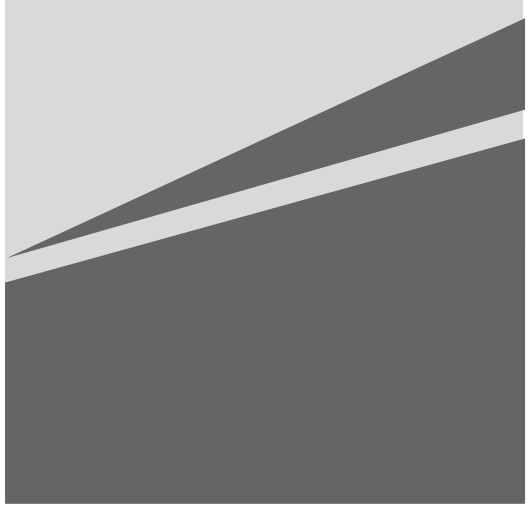


has impacted the teaching work in higher education, making it intensified, flexible and precarious.

KeY-WORdS: TEACHING WORK. COllege education. COUNTER-ReFORMATION. CRISIS.

RESUMEN El presente artículo trata del trabajo docente en el contexto de contrarreforma del Estado brasileño, a partir de las interpretaciones de varios autores sobre la perspectiva de los organismos internacionales, como el Banco Mundial y el Fondo Monetario Internacional, en el marco de las políticas de educación superior en Brasil, situándolas en el contexto neoliberal. La cuestión problema que orientó la investigación fue: cuáles los impactos de la contrarreforma del Estado para el trabajo docente en la educación superior brasileña? El método de investigación fue el materialismo histórico dialéctico, que posibilitó la aproximación de la totalidad y de las contradicciones del fenómeno analizado. Los procedimientos metodológicos utilizados fueron: levantamiento y estudio teórico-bibliográfico sobre la temática, resultando en un abordaje cualitativo. Los resultados indicaron que la contrarreforma del Estado brasileño, impulsada por la reestructuración productiva y bajo la égida de los organismos internacionales, ha impactado en el trabajo docente en la educación superior, haciéndolo intensificado, flexibilizado y precarizado.

PALABRAS ClaVE: TRABAJO DOCENTE. EdUCACIÓN UNIVERSITáRIA. CONTADOR. CRISIS.

\section{INTRODUÇÃo}

l nicialmente, menciona-se a compreensão acerca de que o Trabalho Docente está consubstanciado como parte da totalidade do trabalho sob o espectro do capitalismo. E que suas implicações a respeito do tal fenômeno são múltiplas, particularmente em tempos atuais de crises política, econômica, social, cultural e educacional observadas em diversos países, em especial no contexto brasileiro na atualidade.

Este artigo consiste de revisão da literatura e apresenta como objetivo principal discutir o trabalho docente no contexto de contrarreforma do Estado brasileiro, a partir das interpretações de vários autores sobre a perspectiva dos organismos internacionais, como Banco Mundial e Fundo Monetário Internacional, no âmbito das políticas de educação superior no Brasil, situando-as no contexto neoliberal e de ações do modelo de produção capitalista.
A questão problema que norteou a pesquisa pauta-se na seguinte pergunta: quais os impactos da contrarreforma do Estado para o trabalho docente na educação superior brasileira?

Nesse sentido, a temática é discutida a partir de uma visão crítica fundamentada na dialética materialista histórica, objetivando não somente apresentar o tema, mas discutir em sua totalidade e a partir dos processos de mediação estabelecidos entre o Estado e os organismos internacionais e suas respectivas contradições na política educacional, culminando, assim, em uma abordagem qualitativa do presente tema (FRIGOTTO, 1989).

O corpus teórico desta investigação está dividido em três partes. A primeira apresenta discussões sobre a contrarreforma do Estado e as ações dos organismos internacionais na política educacional brasileira. A segunda discute a respeito da redefinição do papel do Estado e contrarreforma na educação su- 
perior brasileira e seus impactos sobre o trabalho docente. Na terceira parte constam as considerações finais, em que são elencadas algumas reflexões acerca da temática e suas implicações para a atual configuração da política educacional brasileira, especialmente a que toca a educação superior e o trabalho docente em atuais tempos de crise.

\section{A contrarreforma do Estado e as AÇÕES DOS ORGANISMOS MULTILATERAIS INTERNACIONAIS NA POLÍTICA EDUCACIONAL BRASILEIRA}

As políticas educacionais, entendidas como o conjunto de decisões estabelecidas pelo Estado em relação à educação (SAVIA$\mathrm{NI}, 2008$ ), que emergiram principalmente no período pós-redemocratização do Brasil (1988), foram idealizadas com base em uma configuração que expressa a intencionalidade do Estado e seus aliados, com destaque para o Banco Mundial (BM) e o Fundo Monetário Internacional (FMI), entre outros organismos, entendidos e suscitados aqui como Organismos Internacionais (OI).

Destaca-se que as premissas de atuação desses agentes partem da necessidade de reestruturação produtiva, em que as demandas sociais são colocadas em segundo plano ou ditadas a partir da lógica e do interesse do mercado internacional (ANTUNES; PINTO, 2017).

Nessa perspectiva, as intenções do conjunto de diretrizes estabelecidas por esses organismos tendem a promover o fortalecimento do capital e a ampliação das instituições privadas frente às públicas, a partir de um direcionamento pautado no neoliberalismo que, "em nível mundial configura-se como uma reação burguesa conservadora e monetarista, de natureza claramente regressiva, dentro da qual se situa a contrarreforma do Estado" (BEHRING, 2008, p. 129, grifos dos autores).

Destaca-se que, segundo Matos (2008, p. 193), "a ideologia neoliberal surge na Europa Ocidental e América do Norte no pós-II Guerra Mundial, desenvolvendo-se desde o início do século XX a partir da 'Escola Austríaca', fundada por Carl Menger e continuada por Ludwig Von Mises" Seus objetivos consistem na liberdade de Mercado, Estado Mínimo, liberdades individuais, entre outros aspectos. Seus primeiros e principais defensores são Ludwig Von Mises, Milton Friedman, Friedrich Auguste Hayek e Karl Popper. Acredita-se, de acordo com Behring (2008), que a intenção do modelo neoliberal parte de um ajuste mundial e das relações entre "centro e periferia" do mundo do capital.

Assim sendo, no Brasil foi possível perceber um conjunto articulado de ações neoliberais que objetivavam consolidar algumas mediações em território brasileiro, especialmente a partir do período de redemocratização do país, em 1988. Com efeito, as diretrizes e políticas emanadas pelos OI sob a égide neoliberal de menos Estado e mais mercado passaram a permear o cenário político-econômico-social brasileiro.

Segundo Guimarães e Chaves (2015), as estratégias e ações do Estado em parceria com os Organismos Multilaterais passaram a ser vistas com maior intensidade a partir da aprovação da Lei 9.394/1996 (Lei de Diretrizes e Bases da Educação Nacional), em que os interesses de cunho neoliberal eram percebidos com maior intensidade e sob a perspectiva de melhorar as condições de vida em sociedade. No entanto, historicamente, é percebido que esse aporte socioeconômico neoliberal não realiza o que de fato a sociedade necessita, mas busca a todo modo reconstruir-se ${ }^{1}$ e se alavancar no trato social sob os interesses privados advindos do capital.

Nesse sentido, diante das mediações estabelecidas pelo Estado e os OI na atual con-

Utiliza-se a expressão reconstruir-se para dar ênfase ao processo histórico de crises cíclicas do modo de produção capitalista, a exemplo da Crise de 19291932, amplamente conhecida. Ressalta-se que as crises do capital são ancoradas: na superprodução, superacumulação e subconsumo que coexistiram em períodos históricos distintos. Atualmente, o Estado, com os organismos internacionais, visa estabelecer políticas que amorteçam a estrutura cíclica socialmente impactante de crises do capital, dentre eles, destacam-se as políticas educacionais. 
juntura política, econômica, social e educacional, é importante destacar que:

Os organismos financeiros internacionais atuam como porta-vozes dos interesses do capital no campo educativo e na sociedade como um todo, de um lado, disseminando a ideia da necessidade de promover reformas tidas por 'modernizadoras' e 'racionalizadoras'; de outro lado, sendo eles próprios os impositores de tais medidas no campo político, formulando diretrizes e elaborando estratégias políticas, o que, nos anos de 1980 e 1990, passou a servir como importante moeda de troca no plano das relações internacionais (MINTO, 2006, p. 221, grifo dos autores).

Dessa forma, compreende-se que as ações desses organismos tendem a materializar o projeto neoliberal, consubstanciado pelas "reformas" sociais implementadas pelo Estado e seus agentes, mas que na verdade, assumem o espectro político social de contrarreformas com ênfase na reconstrução econômico e no ajuste fiscal. Ressalta-se que é nesse contexto que as contrarreformas educacionais emergem no período pós-redemocratização no Brasil, conforme destacado.

É nesse contexto de crise do capital, de mudanças no mundo do trabalho em função da reestruturação produtiva que começam, de forma efetiva, a serem definidas as reformas na educação brasileira na última década, tendo continuidade nos primeiros anos do novo milênio. As características maiores dessas reformas são as de regulação e controle, em função do caráter que o Estado assumiu, ou seja, de um Estado Avaliador e Regulador. As Reformas na educação seguem essa mesma dinâmica e lógica e afetam consequentemente o trabaIho dos profissionais que atuam na área (MAUÉS, 2006, p. 1).

Em consequência a essa lógica, cita-se que o mundo do trabalho sofreu grandes alterações em sua configuração existencial, de modo que recaíram consequências sobre o conjunto de trabalhadores em suas diversas atividades laborais, particularmente, sobre o trabalho docente que passou a ser concebido pelos vieses epistemológicos elaborados pelos OI e pelo Estado de caráter neoliberal.

Desse modo, com o objetivo de fortalecer tal ideia, o Estado passa a atuar como "um comitê que gerencia os interesses da burguesia" (MARX; ENGELS, 2010). Sob essa vertente, cresce a descentralização do conjunto de atividades desenvolvidas pelo mesmo, sob a prerrogativa inicial promover a divisão de responsabilidades no âmbito social, no entanto, o pano de fundo das práticas de descentralização consiste na crescente desresponsabilização do Estado frente a garantia dos direitos sociais.

Implica destacar que "a descentralização ao nível educativo supõe, por um lado, a transferência das instituições nacionais aos Estados e municípios e, por outro, a decisão de fornecer subsídios do Estado à educação privada" (BIANCHETTI, 1996, p. 102). Tal prerrogativa está pautada na ideia de ação estratégica visando a eficiência das instituições sociais e escolares, de maneira que tende a passar a falsa ideia de que as instituições públicas não conseguem garantir o mínimo de qualidade em seus serviços, tendo, portanto, a necessidade de transferência de papel e atividades para entes privados.

Percebe-se, então, que as ações do Estado estão, cada vez mais, pautadas na implementação de políticas sociais reformistas que atendam às demandas da lógica de reestruturação produtiva sob os ordenamentos dos OI que emergem a partir do interesse do capital. Consubstanciando com essa ideia, cita-se que: 
De um lado, as reformas institucionais são impostas politicamente por elites nacionais e internacionais, por meio de um discurso teórico-ideológico que as apresentam como a única possibilidade real de alcançar o crescimento econômico e a estabilidade sociopolítica, quando não simplesmente para sobreviver. Por outro lado, o mercado real está longe da utopia neoliberal, segundo a qual o livre mercado possui mecanismos de auto-regulação, mediante os quais a procura competitiva do benefício privado leva a um estado social perfeito (CORRAGIO, 2009, p. 82).

Assim, a partir dessas ações reformistas e do conjunto de ideias articuladas entre o Estado e os organismos multilaterais, é que se configuraram as reformas no campo educacional brasileiro. Cabe destacar que a pedagogia propagada por um desses organismos, no caso, pelo Banco Mundial exprime, em essência, uma visão economicista no campo da educação. Suas análises são ancoradas em experiências que se pautam na comparação entre países do Primeiro e do Terceiro Mundo, refletindo, por vezes, uma tendência generalista dos estudos e investigações realizadas, de modo que tais resultados não se aplicam aos países em desenvolvimento, devido à conjuntura diferenciada entre os mesmos. Nesse sentido, destaca-se que:

As várias políticas educacionais implementadas foram pensadas de modo a promover reformas de ensino de caráter nacional, de longo alcance, homogêneas, coesas, ambiciosas em alicerçar projetos para uma 'nação forte': Tratava-se, também, de preparar e formar a população para se integrar às relações sociais existentes, especificamente às demandas do mercado de trabalho, uma população a ser submetida aos interesses do capital que se consolidava no país (SHIROMA; MORAES; EVANGELISTA, 2007, p. 12-3).

Desse modo, considera-se que, diante de tais ações, o que reverberou no campo da política educacional brasileira encontrou materialidade existencial nas parcerias público-privado, na privatização do ensino, na política educacional de mercantilização, no atendimento às lógicas de mercado, na divisão de responsabilidades educacionais - retirando do Estado a figura social de agente que tem por obrigação promover uma educação de qualidade aos brasileiros e brasileiras e, passando a outros atores sociais o papel de cumprir, em "parcerias", a existência da educação no Brasil.

Nessa perspectiva, é cabível expressar que as próprias políticas sociais se agregam aos interesses estratégicos da classe dominante e que se fundamentam sob a vertente neoliberal, no contexto de ação do capitalismo. $\mathrm{O}$ que, em consequência, demonstra o seu antagonismo frente à essência de tais políticas, porque deveriam atender às necessidades do conjunto de sujeitos, em especial os de classe subalterna, mas, o que se observa, são processos de ações hegemônicas na qual se valem de diferentes discursos, slogans e ideologias para impregnar uma nova concepção educativa em prol da construção de um "consentimento ativo" da população (SHIROMA; SANTOS, 2014).

Essa nova concepção educativa parte da coexistência social de uma nova pedagogia da hegemonia, fundamentada pelos interesses neoliberais e em uma nova dimensão educativa do Estado capitalista. Assim, menciona-se que:

[...] sua principal característica é assegurar que o exercício da dominação de classe seja viabilizado por meio de processos educativos positivos. Sua efetividade justifica-se em parte pela força de sua fundamentação teórica, que legitima ini- 
ciativas políticas de organizações e pessoas baseadas na compreensão de que o aparelho do Estado não pode estar presente em todo tempo e espaço e que é necessário que a sociedade civil e que cada cidadão e tornem responsáveis pela mudança da política e pela definição de formas alternativas de ação social (MARTINS, NEVES, 2010, p. 24).

Em consequência a essas ações perversas, é possível considerar que a própria função social da educação, em especial a superior, é posta em risco, pois os ditames sociais e filosóficos concernentes à promoção de uma educação de qualidade e libertadora caem por terra devido à incumbência mercadológica que a educação assume na atualidade e com o respaldo intencional do Estado e dos organismos multilaterais.

Nesse sentido, com o objetivo de dar continuidade à discussão, percebendo-a a partir do contexto neoliberal de contrarreforma fundamentado nas orientações dos organismos multilaterais e no processo de reestruturação produtiva empregado no atual estágio do capitalismo, se tratará, a seguir, acerca dos impactos que esse processo tem ocasionado sobre o trabalho docente na educação superior brasileira.

\section{REDEFINIÇÃo do PAPEL do EsTAdo}

\section{E CONTRARREFORMA NA EDUCAÇÃO}

SUPERIOR BRASILEIRA: IMPACTOS SOBRE O TRABALHO DOCENTE

A crise social vivenciada a partir das consequências advindas das crises do capital, emerge, fez emergir, segundo Coutinho (2012), a proposta de redefinição do papel do Estado sob duas vertentes. A primeira se trata da proposta democrática, que representa os interesses das classes subalternas e tem como objetivo a redefinição do espaço público e o aumento dos mecanismos de socialização e de participação política e democrática da sociedade. A segunda é a proposta liberal- -corporativa, que representa os interesses da burguesia e objetiva aprofundar os processos de desigualdade e exclusão social, bem como, destinar ao mercado a condução das relações sociais e econômicas.

Nessa perspectiva, o Estado e os seus pares, nacionais e internacionais, assumem a proposta da segunda vertente, subordinando-se, por completo, às determinações da aliança entre as grandes burguesias e o capital (MINTO, 2006). A figura do Estado, portanto, passa a estar configurada sob a perspectiva neoliberal, assumindo novas características e consolidando modelos diferenciados de atuação que se apresentam sob duas vertentes principais, no caso, a figura de um Estado Regulador e outra de um Estado Avaliador. Em consonância, o neoliberalismo emprega maior atenção à figura institucional do Estado e o compreende como:

[...] um espaço de mediação entre indivíduos que podem ser por natureza desiguais, mas que estão em condições potenciais de superar essa desigualdade. Neste último caso, a função coercitiva do Estado não se identifica com interesses de classe; forma parte da própria natureza do Estado como instituição encarregada de preservar a sociedade (BIANCHETTI, 1996, p. 79).

Dessa forma, os aspectos relacionados à promoção de desigualdade e competição entre os indivíduos são propalados pelo Estado, de modo que sua natureza, sob a ótica neoliberal, não se identifica com interesses de classe subalternas e suas ações consolidam uma perspectiva social burguesa das relações sociais. Nessa perspectiva, destaca-se que:

A reestruturação econômica e as reformas dos aparelhos de Estado geram, por sua vez, uma apreensão ideológica que tende a se hegemonizar, tornando a própria apreensão, indutora das mesmas trans- 
formações das quais é tributária. Em razão de uma concepção que entende esse processo de redefinição do papel do Estado enquanto delimitador das esferas públicas e privada [...] (MINTO, 2006, p. 218).

Assim, é possível considerar que esses aspectos vertiginosos ultrapassam a natureza social do Estado, e buscam redefinir o seu papel sob o espectro social, político, econômico e educacional. Enfatiza-se que nas "sociedades capitalistas podem ser encontradas estratégias de promoção de políticas sociais que mantêm uma estreita relação com as necessidades de acumulação do capital" (BIANCHETTI, 1996, p. 89). Em síntese, objetivam ampliar a faixa de atuação social do capital inserindo suas proposições perversas nas políticas sociais da atualidade. Nesse sentido, considera-se, portanto, que:

Embora o discurso comum reformista apontasse a possibilidade de ampliar a capacidade de investir em políticas sociais como consequência do 'saneamento fiscal do Estado', as reformas redundaram na perda de espaço das políticas sociais. A necessidade de transferir para a esfera do capital privado - cada vez mais concentrado em poucas mãos - o acesso aos fundos públicos que outrora financiavam tais políticas, reduz, assim, a esfera dos direitos sociais e o 'horizonte' de possibilidades da cidadania, já que, sob o domínio e controle do capital, tais fundos passam a ter como destino exclusivo a ampliação das bases de acumulação (MINTO, 2006, p. 219).

Segundo a perspectiva apresentada, é nítido a observação de um discurso camuflado e falacioso em relação ao conjunto das políticas sociais, bem como, a consequência desse processo que ocasionou em perdas sociais significantes para a sociedade. Nesse sentido, ratifica-se que esse processo "[...] se trata de uma contrarreforma conservadora e regressiva" (BEHRING, 2008, 171), e que atinge o conjunto total das políticas públicas sociais, em especial as políticas educacionais de educação superior pós-redemocratização brasileira.

Acredita-se que a redefinição do papel do Estado e das políticas em curso visam, em essência, materializar a pedagogia da hegemonia (MARTINS; NEVES, 2010), concretizada na proposta da Terceira Via $^{2}$ no âmbito das relações capitalistas estabelecidas no contexto neoliberal, em que um emaranhado ideológico faz-se presente com terminologias que primam por escamotear a real estrutura das relações de classe existentes na sociedade atual, entre os quais destacam-se: a concepção de sociedade do conhecimento, a ideia de substituição do público pelo privado, reformas educacionais, a crescente privatização com finalidades de desburocratizar os atendimentos públicos etc.

Quanto às ações que tocam o processo educativo na totalidade e em seus diversos níveis e modalidades, elas estão intrinsecamente direcionadas às propostas neoliberais e aos ordenamentos estabelecidos pelos organismos internacionais. Desse modo, menciona-se que

As políticas educacionais em curso
estão assentadas em princípios, di-
retrizes e pressupostos que tradu-
zem a opção de sociedade, de edu-
cação e de ser humano adotadas
pelo atual governo e que giram em
torno das determinações oriundas
de organismos internacionais que
apontam a necessidade de ajustar
a educação às reformas do Esta-
do. Uma outra referência trata das

2 A Terceira Via se caracteriza como uma proposta ideológica da social-democracia, que se fundamenta na defesa de uma política econômica conservadora associada a uma política social progressista. É uma terceira via no sentido de que é uma tentativa de transcender tanto a social-democracia do velho estilo quanto o neoliberalismo (GIDDENS, 2001). 
mudanças no paradigma produtivo, como forma de sair da crise do capital. Isso implica colocar a educação como um dos elementos importantes para que o Estado cumpra, nessa ótica, o seu novo papel nos ajustes estruturais e fiscais exigidos por aqueles organismos (MAUÉS, 2006, p. 2).

Dessa maneira, a educação é colocada como elemento de subserviência ao capital, e as redefinições estratégicas estabelecidas pelo Estado e os OI são constituídas a fim de se cumprir os ajustes estruturais estabelecidos por estes.

Nesse sentido, Bianchetti (1996) destaca dois elementos importantes neste processo de mudanças no papel do Estado, sob a ótica neoliberal, a saber: o financiamento e descentralização educacional. O financiamento, na perspectiva apresentada, é tratado a partir do compromisso que os estudantes devem ter com o "investimento" em educação. Ou seja, no âmbito neoliberal, parte do valor destinado à manutenção do sistema escolar deve vir dos estudantes, seja na cobrança de taxas, matrículas, ou tudo o que possa ser oferecido no processo de formação do mesmo. Em consequência, a educação passa a ganhar status de mercadoria numa relação de compra-venda no âmbito do sistema capitalista.

A descentralização se refere aos arranjos de divisão de responsabilidade no âmbito social, de maneira que a figura do Estado tende a ser mínima nas interferências sociais e principalmente econômicas (BIANCHETTI, 1996). Tal ideia se fundamenta na ação estratégica objetivando ocasionar maior eficiência e qualidade nas instituições sociais e escolares.

Assim, corroborando com a ideia apresentada, Adrião (2017, p. 17-8) acrescenta que as estratégias que vigoram atualmente: “[...] passam a compor programas de governos de diversos estados e municípios brasileiros, cujo objetivo é a transferência da gestão da educação pública para o setor privado, seja por meio de parcerias público-privado, ${ }^{3}[\ldots]$, seja através dos contratos de gestão". ${ }^{4}$ Cabe mencionar que tais implicações se desenvolvem tanto no âmbito da educação básica, quanto da superior brasileira.

Diante do que fora apresentado, cita-se que as reverberações desse processo recaem particularmente sobre a educação superior brasileira, sendo que as principais implicações que serão percebidas são avistadas no âmbito do efervescente processo de privatização da educação superior, inserção da lógica de mercado sobre as instituições públicas e particulares, sendo nas últimas de maneira mais expressiva sobre o trabalho docente, de modo que a precarização e a intensificação serão fatores bastantes significantes e vivenciados dentro dessa lógica de "crise" do Estado.

Consubstanciando com essa situação, percebe-se que a atuação docente, no âmbito do neoliberalismo e das ressignificações presentes na mudança do papel da universidade e do ensino superior, ocorre de uma maneira que busca envolver os interesses mercadológicos e atender a aspectos que estimulem a competição e, por conseguinte, promovendo a desigualdade social no âmbito das universidades, especialmente, as públicas brasileiras (SGUISSARDI, 2009).

No âmbito das IES privadas, particularmente as que ofertam Educação a Distância, percebe-se que o trabalho do professor universitário ganha novas demandas e responsabilidades, o exemplo disso está na concretização do processo de desregulamentação na profissão docente. O professor, nesse caso, passa a assumir o papel de "tutor", obriga-se a assumir uma demanda educacional com

3 A parceria público-privada (PPP): "refere-se aos acordos entre as Organizações da Sociedade Civil de Interesse Público (OSCIP) e poder público. Esta medida passa a regular a contratação e remuneração pelo Estado de entidade do Terceiro Setor para a realização de atividades relacionadas às políticas sociais, como a educação.” (ADRIÃO, 2017, p. 22).

4 O contrato de gestão: "é um dispositivo jurídico que inaugura a possibilidade de compromisso institucional entre o Estado e uma entidade pública-estatal (agências executivas) ou uma entidade pública não estatal (organizações sociais)." (ADRIÃO, 2017, p. 21). 
exorbitante contingente de alunos por sala de aula, carga horária flexível - o que implica direto no quesito remuneração e valorização docente, sua força de trabalho passa a ser vendida não sob o espectro de um salário específico, mas por hora/aula trabalhada, consubstanciando em um processo de flexibilização do trabalho docente. Além disso, a carga de cobrança pedagógico-institucional prima por direcioná-lo à pratica docente com vistas a estabelecer o ensino e aprendizagem objetivando formar um cidadão produtivo, flexível, dotado de competências e habilidades que o coloquem em boas condições de competir para o mercado do trabalho - o que nem sempre acontece dado a conjuntura em que é desenvolvido o processo educativo (VIEIRA; ARRUDA, 2016).

Agregado a isso, o trabalho docente, em sua totalidade, passa a estar inserido na lógica da produtividade exacerbada, na busca por mais e melhores resultados institucionais e pessoais, almejando, em muitos momentos o alcance de aprovações em editais que remuneram por produtividade e por produtos criados, como artigos e projetos educacionais.

Nessa perspectiva, a presença de um atual contexto de crises e incertezas no Brasil - principalmente a partir de um conjunto de reformas implementadas pelo Estado brasileiro, como no caso da aprovação da Emenda Constitucional (EC) 95/2016, que estabeleceu o congelamento dos gastos públicos por vinte anos e da Lei Federal n. 13.467, de 13 de julho de 2017, que altera a consolidação das leis do trabalho (CLT) e traz, em essência, novos padrões das relações trabalhistas que asseveram a lógica processual do trabalho, colocando em risco os direitos socialmente conquistados pelos trabalhadores.

Em consequência, considera-se que os impactos dessas contrarreformas do Estado para o trabalho docente na educação superior brasileira se mostram agregadas ao processo crescente de flexibilização do mundo do trabalho, intensificação do trabalho docente e precarização ${ }^{5}$ das condições e nas relações de trabalho.

Destaca-se que o processo de flexibilização do mundo do trabalho diz respeito às condicionantes impostas pela configuração do modelo produtivo atual, no caso, o Toyotismo, ${ }^{6}$ sobre o conjunto de trabalhadores, de modo que "[...] para a efetiva flexibilização do aparato produtivo, é também imprescindível a flexibilização dos trabalhadores. Direitos flexíveis, de modo a dispor desta força de trabalho em função direta das necessidades do mercado consumidor" (ANTUNES, 2009, p. 41). Percebe-se, então, que a flexibilização do mundo do trabalho atual contribui com os problemas vinculados às ações de contrarreformas do Estado para o trabalho docente na educação superior brasileira.

Um dos problemas que merecem destaque trata-se do processo de intensificação, em especial do trabalho docente, que diz respeito "a condição pela qual requer-se mais esforço físico, intelectual e emocional de quem trabalha com o objetivo de produzir mais resultados (produto), consideradas constantes a jornada, a força de trabalho empregada e as condições técnicas" (DAL ROSSO, 2008, p. 42). Desse modo, considera-se que tal processo implica diretamente na conjuntura atual do trabalho docente desenvolvido na educação superior brasileira.

Nessa perspectiva, concorda-se que "a intensificação representa uma das formas tangíveis pelas quais os privilégios de traba-

\footnotetext{
O processo de precarização está vinculado à existência de problemas de ordem conjuntural como a falta de infraestrutura materializada na ausência de laboratórios de pesquisa, de livros para consulta acadêmica, de salas de aula, de recursos primários, entres outros (OLIVEIRA; PIRES, 2014).

6 “É uma forma de organização do trabalho que nasce na Toyota, no Japão pós-45, e que, muito rapidamente, se propaga para as grandes companhias daquele país. [...] É uma produção muito vinculada à demanda. [...]. Fundamenta-se no trabalho operário em equipe, com multivariedade de funções. [...]. A produção se estrutura num processo produtivo flexível. [...]. Tem como princípio o just in time, o melhor aproveitamento possível do tempo de produção" (ANTUNES, 2009, p. 45).
} 
Iho dos trabalhadores educacionais são degradados" (APPLE, 1995, p. 39). Assim, suas consequências representam a degradação dos privilégios de trabalho dos docentes. Enfatiza-se que em "tempos de crise", como o atual momento, tais privilégios tendem a serem suprimidos cada vez mais.

Observa-se, portanto, a ausência de condições objetivas que preconizem o processo educacional desagregado da lógica neoliberal e dos ordenamentos impingidos pelo Estado e pelos organismos internacionais (SGUISSARDI; SILVA JÚNIOR, 2009).

Outro fator importante está presente na mudança do papel da universidade pública, esta que passa a assumir o caráter de universidade neoprofissional, heterônoma, competitiva e desigual dentro dos seus próprios processos acadêmicos, conforme destacado.

Faz-se presente a transformação da ideia de universidade como instituição social em universidade como organização social, sinônimo de empresa econômica, heterônoma, sem estabilidade de emprego e trabalho dos docentes, o que lhes subtrai toda a liberdade de pensamento, de ensino e pesquisa (SGUISSARDI, 2009, p. 338-9).

Tal perspectiva parte da ideia de influência de setores externos à educação, principalmente o Estado e a indústria, na definição da missão, da agenda e dos produtos das universidades (SGUISSARDI, 2009). Ou seja, percebe-se a nítida consolidação do processo neoliberal, reformulando o caráter social das instituições superiores de educação, especialmente as instituições públicas, como no caso das universidades.

Nesse sentido, diante desse espectro socioeducacional, é preciso que se avance nas compreensões, leituras, discussões, interpretações, debates, objetivando a materialização concreta de ações contra hegemônicas e contra o sistema perverso em vigor na atualidade, pensando em uma proposta socioeducativa para além do capital (MÉSZÁROS, 2002). Por fim, diante desse cenário de perdas sociais e retrocessos, considera-se que grandes são os impactos que circundam o papel das universidades, e na tangente do processo de trabalho estabelecido pelo conjunto de docentes dessas referidas instituições, e maiores ainda são os desafios daqueles que lutam por uma educação pública, laica e de qualidade no Brasil.

\section{CONSIDERAÇões FINAIS}

Diante da discussão apresentada e do objetivo proposto, é possível mencionar que diversas transformações, desde o período pós-redemocratização brasileira, incidem sobre as políticas públicas sociais brasileiras e, em especial às políticas educacionais. Nesse sentido, os impactos dessas transformações alcançaram diversos âmbitos e proporções, nesse caso, particularmente sobre o trabalho docente. A educação, nesse processo, teve sua função social ressignificada, passando de uma lógica formativa para a mercadológica. Em consequência disso, as instituições públicas, cada vez mais, vivem o processo de descompromisso por parte do Estado no que tange à manutenção e ao desenvolvimento político institucional de qualidade.

Somado a isso, tem-se a materialização de relações mercadológicas sobre o espectro educacional e a privatização crescente. Ademais, no tocante aos impactos universitários, cita-se que o trabalho docente foi realocado em seu papel. Além disso, a lógica neoliberal, fundamentada nos pressupostos de reestruturação produtiva e flexibilização do mundo do trabalho, contribui significativamente para o processo de precarização e intensificação do trabalho docente na atualidade.

Assim, percebe-se a existência de um cenário perverso instaurado, criado e efervescido pelo neoliberalismo, pelo capital, pelo Estado e pelos OI. Porém, sabendo que "as novas configurações sociais não surgem do abstrato, pois são fruto da ação humana e, como tal, têm história socialmente constru- 
ída. Sendo assim, são passíveis de mudanças" (AZEVEDO, 2001, p. 18-9), acredita-se que pela dialética de construção histórica, os mecanismos de resistências e lutas sejam importantes no combate à realidade presente nesse cenário que atinge a sociedade e, particularmente o papel do Estado, as políticas educacionais direcionadas para a educação superior e o trabalho docente na atualidade.

Por fim, acredita-se que os ordenamentos e as políticas estabelecidas pelos orga- nismos multilaterais internacionais tendem a maximizar as desigualdades existentes em diversos campos sociais nos países em desenvolvimento e, principalmente, se comparados aos desenvolvidos. Todavia, em uma perspectiva Gramsciana, enfatiza-se a importância do papel dos intelectuais orgânicos da classe trabalhadora no combate e nas resistências à essas políticas perversas implementadas pelo capital e seus agentes.

\section{REFERÊNCIAS}

ADRIÃO, T. A privatização da educação básica no Brasil: considerações sobre a incidência de corporações na gestão da educação pública. In: ARAÚJO, L.; PINTO, J. M. (Orgs.). Público x privado em tempos de golpe. São Paulo: Fundação Lauro Campos, 2017.

ANTUNES, R. Os sentidos do trabalho: ensaio sobre a afirmação e a negação do trabalho. São Paulo: Boitempo Editorial, 2009, 287 p.

. PINTO, Geraldo Augusto. A fábrica da Educação: da especialização taylorista à flexibilização toyotista. São Paulo: Cortez, 2017, 117 p.

APPLE, M. Trabalho docente e textos: economia política das relações de classe e gênero. Porto Alegre: Artes Médicas, 1995.

AZEVEDO, J. A educação como política pública, 2. ed. Campinas: Autores Associados, 2001, 79 p.

BEHRING, E. R. Brasil em contrarreforma: desestruturação do Estado e perda de direitos, 2. ed. São Paulo: Cortez, 2008, 304 p.

BIANCHETTI, R. G. O modelo neoliberal e as políticas educacionais, 2. ed. São Paulo: Cortez, 1996, $120 \mathrm{p}$.

BRASIL. Congresso/Senado. EC n. 95, de 15 de dezembro de 2016. Altera o ADCT para instituir o Novo Regime Fiscal, e dá outras providências. Diário Oficial da União, Brasília, DF, 15 dez. 2016. Disponível em: http://www.presrepublica.jusbrasil.com.br/legislacao/ 415733850/emenda-constitucional-95-16. Acesso em: 21 jan. 2018.

. Presidência da República. Lei n. 13.467, de 13 de julho de 2017. Altera a Consolidação das Leis do Trabalho (CLT). Disponível em:

http://www.planalto.gov.br/ccivil_03/_at02015-2018/2017/lei/L13467.htm. Acesso em: 21 jan. 2018.

CORAGGIO, J. L. Propostas do banco mundial para a educação: sentido oculto ou problemas de concepção? Tradução de Mônica Corullón. In: TOMMASI, L. de; WARDE, M. J.; HADDAD, S. (Orgs.). O Banco Mundial e as políticas educacionais, 6. ed. São Paulo: Cortez, 2009.

COUTINHO, C. N. O Estado brasileiro: gênese, crise, alternativas. In: COUTINHO, C. N. (Org.). Contra a corrente: ensaios sobre democracia e socialismo, 2. ed. revista e atualizada. São Paulo: Cortez, 2012. 
DAL ROSSO, S. Mais Trabalho!: a intensificação do labor na sociedade contemporânea. São Paulo: Boitempo, 2008, 207 p.

FRIGOTTO, G. O enfoque da dialética materialista histórica na pesquisa educacional. In: FAZENDA, Ivani (Org.). Metodologia da pesquisa educacional. São Paulo: Cortez, 1989. p. 71 - 90.

GIDDENS, A. A terceira via e seus críticos. Rio de Janeiro: Record, 2001, 189 p.

GUIMARÃES, A. R.; CHAVES, V. L. J. A intensificação do Trabalho Docente Universitário: aceitações e resistências. Revista Brasileira de Política e Administração da Educação (RBPAE), v-31, n.3, p. 567-586, set./dez. 2015. Disponível em: http://seer.ufrgs.br/index.php/rbpae/article/ view/59914/37019. Acesso em: 9 fev. 2018.

MARTINS, A. S.; NEVES, M. L. W. A nova pedagogia da hegemonia e a formação/atuação de seus intelectuais orgânicos. In: NEVES, M. L. W.; MARTINS, A. S. (Orgs.). A direita para o social e a esquerda para o capital: intelectuais da nova pedagogia da hegemonia no Brasil. São Paulo: Xamã, 2010.

MARX; K. ENGELS, F. Manifesto Comunista. São Paulo: Boitempo, 2010, 68 p.

MATOS, S. T. S. Conceitos primeiros de neoliberalismo. Revista Mediações. Mediações, v. 13, n.1-2, p. 192-213, jan./jun. e jul./dez. 2008. Disponível em: http://www.uel.br/revistas/uel/index. $\mathrm{php} / \mathrm{mediacoes} / \mathrm{article/viewFile/3314/2716}$. Acesso em: 20 fev. 2018.

MAUÉS, O. A reforma da educação superior e o trabalho docente. VI Seminário da Redestrado - Regulação Educacional e Trabalho Docente. Rio de janeiro, 2006. Disponível em:http://www. fae.ufmg.br/estrado/cd_viseminario/trabalhos/eixo_tematico_1/a_reforma_da_educ_superior. pdf. Acesso em: 10 fev. 2018.

MÉSZÁROS, I. A educação para além do capital, 2. ed. São Paulo: Boitempo, 2002, 126 p.

MINTO, L. W. As reformas do ensino superior no Brasil: o público e o privado em questão. Campinas: Autores Associados, 2006, $318 \mathrm{p}$.

OLIVEIRA, L. J. PIRES, A. P. V. Da precarização do trabalho docente no Brasil e o processo de reestruturação produtiva. Revista do Direito Público. Londrina, v. 9, n. 1, p. 73-100, jan./ abr. 2014. Disponível em: http://www.uel.br/revistas/uel/index.php/direitopub/article/viewFile/17128/14324. Acesso em: 10 fev. 2018.

SAVIANI, D. Política educacional brasileira: limites e perspectivas. Revista de Educação PUC-Campinas, Campinas, n. 24, p. 7-16, jun. 2008. Disponível em: http://periodicos.puc-campinas. edu.br/seer/index.php/reveducacao/article/view/108/96. Acesso em: 10 fev. 2018.

SGUISSARDI, V. A universidade brasileira no século XXI: desafios do presente. São Paulo: Cortez, 2009, $341 \mathrm{p}$.

. SILVA JÚNIOR, J. dos R. Trabalho intensificado nas federais: pós-graduação e produtivismo acadêmico. São Paulo: Xamã, 2009, 270 p.

SHIROMA, E. O.; MORAES, M. C. M. de; EVANGELISTA, O. Política educacional, 4. ed. Rio de Janeiro: Lamparina, 2007, 128 p.

. SANTOS, F. A. dos. Slogans para a construção do consentimento ativo. In: EVANGELISTA, O. (Org.). O que revelam os slogans na política educacional, 1. ed. Araracuara: Junqueira \& Marin, 2014. 
VIEIRA, M. N.; ARRUDA, E. P. Estado Capitalista, Trabalho Docente e Educação A Distância. Revista @rquivo Brasileiro de Educação, Belo Horizonte, v.4, n. 7, jan./abr. 2016. Disponível em: http://periodicos.pucminas.br/index.php/arquivobrasileiroeducacao/article/download/P.23187344.2016v4n7pg/10279. Acesso em: 21 jun. 2018.

\section{SOBRE OS AUTORES}

\section{RODRIGO BARBOSA BASTOS}

Licenciado e Bacharel em Geografia (UNIFAP). Especialista em Políticas Educacionais (UNIFAP). Mestrando em Educação, na linha de Políticas Educacionais, pela Universidade Federal do Amapá (UNIFAP). Membro do Grupo de Estudos e Pesquisas Marxismo, Trabalho e Políticas Educacionais (GEMTE).

E-mail: rodrig018_bastos@hotmail.com

\section{ILMA DE ANDRADE BARLETA}

Professora do magistério superior na Universidade Federal do Amapá (UNIFAP). Doutora em Educação pela Universidade Federal do Pará (UFPA), atua na Graduação e Pós-Graduação. Vice-líder do Grupo de Estudos e Pesquisas Marxismo, Trabalho e Políticas Educacionais (GEMTE).

E-mail: ilmabarleta@bol.com.br

Recebido em: 30/04/2018

Aceito em: 29/06/2018 